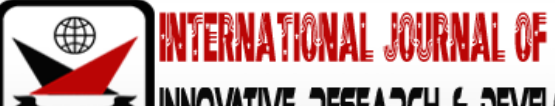

ISSN 2278 - 0211 (Online)

\section{Perceived Challenges and Recommendations for Overcoming Challenges by Diploma in Adult Education Student, Teachers through Open and Distance Learning in Tanzania: A Case of Institute of Adult Education, Dodoma Centre, Tanzania}

\section{Dr. Juhudi K. Cosmas}

Lecturer, Department of Education, College of Education, University of Dodoma, Tanzania

\section{Abstract}

This study investigated the challenges and recommendations for overcoming such challenges as experienced and perceived by student-teachers for Diploma in Adult Education through Open and Distance Learning (ODL) at Institute of Adult Education Dodoma Region Centre, Tanzania. The study employed qualitative approach. The main data collection techniques were open ended questionnaires. Tables, frequencies, percentages and description were used present the open ended questionnaire findings. The findings indicated that ODL student-teachers for Diploma in Adult Education faced a number of challenges in their course of learning. The most perceived challenges were grouped into: Individual (meeting other activity demands while learning, failure to balance time for learning and doing other activities, financial limitations, lack of skills of using computers and internets hence difficulty to search online learning materials); institutional (absence of internets and networks in rural and remote areas, and absence of computer and internet server for students at the ODL Centre); and instructional (delayed feedback, and insufficient of study materials). In recommendations for overcoming such challenges, it was perceived that the Government should support in-service student-teachers financially; ODL Centre should provide sufficient learning materials on time, equip ODL student-teachers with skills of using computers and install computers and internet server at ODL Centre; ODL centres should be established at least at district levels in Dodoma Region and others regions; and ODL facilitators should establish suitable mechanisms of helping ODL student-teachers and provide feedback timely. The study concludes with the views that many Tanzanians, specifically teachers, benefit and will continue to benefit from ODL programmes. This calls a combined action of Government, ODL centres and other ODL stakeholders to collaborate for resolving the existing challenges.

Keywords: Open learning, distance learning, challenges, Institute of Adult Education

\section{Background of the Study}

\subsection{Introduction}

Worldwide, open and distance learning (ODL) is seen to offer new ways in which to widen access to education and it has a decisive role to play in meeting the demand for education (James, Tynan, Baijnath \& Teixeira, 2013). Importantly, ODL can contribute to the global commitment to provide quality and inclusive education for everyone worldwide, as expressed in the Sustainable Development Goals (SDGs), especially SDG 4 and its targets (United Nations Educational, Scientific and Cultural Organization (UNESCO), 2016). SDG 4 states to 'ensure inclusive and quality education for all and promote lifelong learning' (UNESCO, 2016, p. 6) by 2030. ODL is a functional strategy in different ways, for example in:

- Providing equivalent education to children and adults who do not get opportunity in formal education system and those who drop out of school due to various reasons;

- complementing government efforts of achieving Sustainable Development Goals (SDGs), especially SDG 4 and its targets;

- Providing education to disadvantaged groups, on cross-cutting issues such as HIV/AIDS, poverty reduction, environment and good governance and other issues related to such.

ODL is currently mainstreamed in a new learning landscape created by the availability of technologies supporting flexible, accessible and increasingly personalized learning (James et al, 2013). As a vehicle of social and economic development, ODL is today one of the most rapidly growing fields of education and training (Özgür \& Koçak, 2016). It meets the increasing need for education; offers equality of opportunity in education with low-cost education; offers the opportunity of access to education for people that cannot get on-school education; and increase the opportunities of vocational education, training teachers and contributing to the level of development of a country (Özgür \& Koçak, 2016). 


\subsection{Conceptualizing Open and Distance Learning}

It important to note that current operating concept of ODL originate from two fundamental concepts that is, 'open learning' and 'distance learning' which first should be understood. According to Onwe (2013), at present there is no a universally accepted definition of the concept 'open learning'. While some educationists argue that 'open learning' simply means open entry and access to learning opportunities and the removal of barriers to learning opportunities, others argue that 'open learning' can be substituted for flexible learning (Onwe, 2013). According to Komba (2009), openness is considered in relation to intake, participation, progression, completion and achievement. Barriers to learning opportunities include the student's economic circumstances, socio-cultural factors, academic qualifications as well as teaching approaches (Komba, 2009).

On the other hand, as Komba (2009) asserts, distance learning is an approach that takes learning to the many learners who are separated by time and space, from those who are teaching. It is a mode that has a high potential for transcending barriers that are caused by distance, time, and age; thus facilitating lifelong learning. It portrays the possibility of communication between participants in a learning system across time and space through technologies. It is 'the various forms of teaching and learning at all levels which are not under the continuous, immediate supervision of tutors present with their learners in lecture rooms' (Holmberg (1990) as cited by Onwe, 2013, p. 123). Through distance learning the learner enjoys a high degree of autonomy in deciding what, when and how to learn (Komba, 2009).

Therefore the concept of ODL suggests learning approach designed to reach learners in their homes, offices and shops, where learning proceeds without attending formal classes in person, no matter where or when they want to study (Soetan, Udoh \& Suleiman, 2015). Additionally, ODL provides education for all, promotes lifelong learning, and improves on the economies of scale in education management (Onwe, 2013; Özgür \& Koçak, 2016). From this stand, features of ODL can be best understood as a 'flexible, cost-effective, and learner-centred educational system. ODL is a 'learner-oriented system that allows greater flexibility in learning while students continue with their regular work... It is learner-centred as it aims at providing answers to academic questions and problems of learners, not the other way round' (Onwe, 2013, p. 124).

According to Özgür \& Koçak (2016), when flexible learning is considered, two important aspects can be mentioned: Flexibility with regard to time and place, and flexibility with regard to student needs. First aspect - the desire to make education less dependent on time and place - is mainly related to the increasing number of people who combine study and work because of staying well prepared for changes in job requirements, improving career perspectives and realizing personal growth. The second aspect of flexibility is related to the idea that products and services are more and more produced on demand according to the specifications of an individual client.

\subsection{Prospects of Open and Distance Learning}

As Basaza, Milman and Wright (2010) point out, ODL programme provides flexibility for learners and enables them to complete their courses at their own convenience, reduces overcrowdings on the institution premises hence reduces the need for educational buildings, reduces transportation costs incurred by learners, allows learners to remain with their families and communities, and enables tuition fees to be set relatively low when compared to on-campus tuition fees.Rubanju (2008) notes that in the traditional lecture hall or classroom, theory and applications (practices) are not linked. Learning via ODL programme allows learners to apply theories to their own settings and to observe the effect on their environment. This emphasizes educational theories and practices that are suitable for the current learner's context.

ODL does not restrict learners according to the entry requirements for age background, occupational status and marital status; it is affordable and flexible programme, which is not common in conventional universities and colleges of education (Soetan et al., 2015). Additionally, according to James et al. (2013), ODL does not only benefit learners, but also to institutions and employers as summarized in figure 1. 
For the learners

- Increased access and flexibility

- Ability to combine work and education

- Reduced travel time and costs

- More learner-centred approach

- Relevance to authentic learning needs

- Enrichment, higher quality and new ways of interaction

- Acquisition of $21^{\text {st }}$ century skills necessary for the workplace.

For institutions

- Attracting global underserved populations of potential

- Students

- Improved teaching quality

- Support for continuing education

- $\quad$ Reduced need for bricks and mortar infrastructure.

For employers

- High quality and usually cost effective professional development in the workplace

- Reduced travel time and costs

- $\quad$ Easy, regular upgrading of skills

- Increased productivity

- Development of a new learning culture

- Sharing of costs and training time

- Increased portability of training.

For governments potential to

- Increase capacity and cost-effectiveness of education and training systems

- Reach target groups with limited access to conventional education and training

- Reduce gender inequality by allowing women to access education through distance learning, while staying at home with their families and in their own countries and communities

- Ensure the connection of educational institutions and curricula to the emerging networks and information resources

- Support and enhance the quality and relevance of existing educational structures and programs

- Promote innovation and opportunities for lifelong and life-wide learning.

Figure 1: Benefits of ODL Programmes

Source: James et al. (2013, p. 5)

\subsection{Challenges Associated with Open and Distance Learning}

Challenges associated with ODL are related to attitude that learners enroll in order to obtain a qualification and/or a promotion; some enroll in courses with the attitude that ODL is easy; some learners drop out or do not graduate; and some lecturers believe that ODL learners do not need extra support (Basaza et al., 2010). According to Basaza et al. (2010), the success of ODL is also inhibited by poor infrastructure, the relatively high cost of an education, an irrelevant curriculum, inadequate expertise in ODL, and poor attitudes towards distance learning.

\subsection{Institute of Adult Education and ODL in Tanzania}

The history of ODL in Tanzania can be traced back to the days of colonialism and after independence with the number of players. Institute of Adult Education is one of the most popular institutions in ODL programmes (Komba, 2009). According to Institute of Adult Education (2008), the Institute was established in 1960 as an extra mural studies section of Makerere University College, under the University of London. In 1963, the Institute was upgraded to a department and placed under the Dar es Salaam University College. Later on it became an autonomous institution established by Parliamentary Act No. 12 of 1975 under the then Ministry of National Education (Institute of Adult Education, 2008). ODL was established by Institute with the goal of providing quality education to citizens who are unable to access education through formal education system. It offers, among others, Certificate Course in Law, Ordinary and Advanced level secondary education certificates and Teacher Education and Community Development. This study investigated the perceived challenges and recommendations for overcoming such challenges by ODL student-teachers by student-teachers as they pursue diploma in adult education through ODL at Institute of Adult Education - Dodoma Centre.

\subsection{Purpose of the Study}

The purpose of the study was to investigate the perceived challenges and recommendations for overcoming such challenges by ODL student-teachers as they pursue Diploma in Adult Education. The study specifically, intended to answer two questions: i) what are the perceived challenges by ODL student-teachers as they pursue Diploma in Adult Education? ii) What are the perceived recommendations for overcoming challenges by ODL student-teachers as they pursue Diploma in Adult Education? 


\section{Methodology}

\subsection{Approach and Design of the Study}

This study employs a qualitative paradigm. Within the qualitative paradigm, among other things, the study is characterized by collecting data in participants' natural contexts and reporting multiple perspectives in wholeness (Clarke \& Braun, 2013; Stake, 2010). This implies that this qualitative study provides the researcher with in-depth knowledge and understandings of multiple perceptions of participants in their contexts or environments. Therefore, this study was conducted in the qualitative paradigm with the assumption that there is no only one correct version of reality or knowledge, instead, it comes from a perspective of multiple versions of reality - even for the same person - and that these versions are very closely linked to the context they occur in (Braun \& Clarke, 2013).

The study was guided by the phenomenological design informed the study procedures to investigate the challenges faced student-teachers studying diploma in adult education through ODL and the perceived solutions for such challenges. Phenomenology design is concerned with the study of experiences from the perspective of the participants. It provides a deep understanding of a phenomenon as experienced by several participants of the study (Creswell, 2007). This means that it views problem under study from the first order perspective, in which the researcher describes the problem as it is through the eyes of the participants.

\subsection{Sampling and Sample Size}

The idea behind qualitative study is to purposefully select participants of the study that best help the researcher to understand the problem and question from the point of view of the participants of the study (Creswell, 2007). This study employed purposeful sampling technique to select the participants of the study. The study employed convenience sampling strategy (Creswell, 2007; Gall, Gall \& Borg, 2005; 2007).

Convenience sampling strategy helped the researcher to select the participants at the Institute of Adult Education - Dodoma centre who were available and likely to participate. Fifteen (15) participants, who all were in second year pursing Diploma in Adult Education, formed the sample size of the study. All participants participated in questionnaires.

\subsection{Data Collection and Analysis}

Data were collected from participants who had experiences with the challenges faced student-teachers studying diploma in adult education through ODL and the perceived recommendations for overcoming challenges by ODL studentteachers through open ended questionnaires. In open ended questionnaires, the participants were asked to list the perceived challenges and recommendations for improving situation as they pursued Diploma in Adult Education through ODL.

In data collection process, the researcher was the main research instrument. He assumed the role of the guider, motivator and interviewer. The data collected through open ended questionnaires were subjected to content analysis. The analysis of data was carried out by the researcher. Two themes were deductively predetermined by the researcher. The themes were: i) Perceived challenges faced ODL student-teachers as they pursued Diploma in Adult Education and ii) perceived recommendations for overcoming challenges by ODL student-teachers as they pursued Diploma in Adult Education.

\section{Findings}

In this study, the participants were asked to list the perceived challenges and recommendations for improvement. This section presents the findings of the perceived challenges by ODL student-teachers as they pursued Diploma in Adult Education and their perceived recommendations for overcoming such challenges. The section consists of two sub-sections reflecting two themes: i) Perceived challenges by ODL student-teachers and ii) perceived recommendations for overcoming challenges by ODL student-teachers.

\subsection{Perceived Challenges by ODL Student-Teachers}

The participants were asked to list what they perceived to be challenges as they pursued Diploma in Adult Education. The listed perceived challenges were organized into three sub-themes predetermined by the researcher: Individual challenges; institutional challenges; and instructional challenges.

\subsubsection{Individual Challenges}

As indicated in Figure 1 from open ended questionnaires, the perceived individual challenges by ODL studentteachers as they pursued their studies involved the following: Meeting other activity demands while learning, failure to balance time for learning and doing other activities, limited time to study, financial limitations, lack of skills of using computers and internets, difficulty of getting learning materials, transport problems and costs, family care and children rearing while learning, family and marriage problems during learning period.

Among the challenges, meeting other activity demands while learning, failure to balance time for learning and doing other activities, limited time to study, financial limitations, and lack of skills of using computers and internets received greater attention from the participants. Majority of participants, over half ( $53 \%$ and above), indicated that these were serious challenges. Similarly, difficulty of getting learning materials, transport problems and costs, family care and children rearing while learning, and family and marriage problems during learning period received lesser attention (below $33 \%$ ) from the participants. 


\subsubsection{Institutional Challenges}

The perceived institutional challenges by ODL student-teachers, as indicated in Figure 1 from open ended questionnaires, included the following: Absence of internets and networks in rural and remote areas, absence of computers and internet server at the ODL Centre, few ODL centres (there is only one ODL Centre) in the Region. Among these challenges, absence of computers and internet server for learners at the ODL Centre received greater attention (about 80\%) followed by absence of internets and networks in rural and remote areas (about 53\%) from the participants. Few ODL centres received lesser attention of $33.5 \%$ from the participants.

\begin{tabular}{|c|c|c|c|}
\hline \multirow[b]{2}{*}{$\mathbf{S} / \mathbf{N}$} & \multirow{2}{*}{ Type of Challenge } & \multicolumn{2}{|c|}{$\mathbf{N}=15$} \\
\hline & & Frequency & Percentage \\
\hline 1 & Meeting other activity demands while learning & 9 & 60 \\
\hline 2 & Limited time to study & 10 & 66.7 \\
\hline 3 & Failure to balance time for learning and doing other activities & 8 & 53.3 \\
\hline 4 & $\begin{array}{l}\text { Financial limitations } \\
\end{array}$ & 8 & 53.3 \\
\hline 5 & Difficulty of getting learning materials & 5 & 33.3 \\
\hline 6 & Transport problems and costs & 3 & 20 \\
\hline 7 & Lack of skills of using computers & 8 & 53.3 \\
\hline 8 & Absence of internets and networks in rural and remote areas & 8 & 53.3 \\
\hline 9 & Absence of computers and internet server at the ODL Centre & 12 & 80 \\
\hline 10 & Few ODL centres (there is only one ODL Centre) & 5 & 33.3 \\
\hline 11 & Short time for face to face sessions & 2 & 13.3 \\
\hline 12 & Family care and children rearing while learning & 3 & 20 \\
\hline 13 & Family problems (e.g. marriage problems) during learning period & 1 & 6.7 \\
\hline 14 & Insufficient and delay of study materials. & 6 & 40 \\
\hline 16 & Lack of help from facilitators & 3 & 20 \\
\hline 17 & Delay of feedback from the Centre and facilitators & 2 & 13.3 \\
\hline
\end{tabular}

Table 1: Perceived Challenges Faced ODL Learners from Open Ended Questionnaires

Source: Field Data 2018

\subsubsection{Instructional Challenges}

The perceived instructional challenges were such as short time for face to face sessions, lack of frequent help from ODL facilitators, insufficient and delay of study materials, and delay of feedbacks from the Centre and ODL facilitators. Although, these challenges received lesser (below 40\%) attention from the participants, the insufficiency and delayed learning materials received more attention (about 40\%) from the participants, and other had almost equal distribution of attention (of between 13\% - 20\%).

\subsection{Perceived Recommendations for Overcoming Challenges by ODL Student-Teachers}

As it was to perceived challenges, the participants were asked to list the perceived recommendations for overcoming challenge as they pursued Diploma in Adult Education as indicated in Table 1. The listed perceived recommendations were organized into three sub-themes predetermined by the researcher: Overcoming individual challenges, overcoming institutional challenges and overcoming instructional challenges.

\begin{tabular}{|l|l|l|l|}
\hline \multirow{2}{*}{ S/N } & \multicolumn{1}{|c|}{ Type of Recommendation } & \multicolumn{2}{c|}{ N = 15 } \\
\cline { 3 - 4 } & \multicolumn{1}{|c|}{} & Frequency & Percentage \\
\hline 1 & Government should support in-service trainees financially & 8 & 53.3 \\
\hline 2 & ODL Centre should provide sufficient learning materials & 5 & 33.3 \\
\hline & $\begin{array}{l}\text { ODL Centre has to establish computer courses to equip ODL learners with } \\
\text { skills of using computers }\end{array}$ & 8 & 53.3 \\
\hline 4 & Government and ODL centre should support the transport costs & 2 & 13.5 \\
\hline 5 & $\begin{array}{l}\text { Government to ensure that internets and networks in rural and remote } \\
\text { areas should be available }\end{array}$ & 7 & 46.7 \\
\hline 6 & ODL Centre should install computers and internet server for students & 12 & 80 \\
\hline 7 & $\begin{array}{l}\text { Government should establish ODL centres at least at district levels in } \\
\text { Dodoma Region and other regions }\end{array}$ & 5 & 33.5 \\
\hline 8 & ODL Centre should supply sufficient learning materials on time & 5 & 33.3 \\
\hline 9 & Time for face to face sessions should be extended & 2 & 13.3 \\
\hline 10 & $\begin{array}{l}\text { ODL facilitators should establish mechanisms of helping ODL learners in } \\
\text { case of a need }\end{array}$ & 1 & 6.7 \\
\hline 11 & The ODL Centre and facilitators should provide feedback timely & 1 & 6.7 \\
\hline
\end{tabular}

Table 2: Perceived Recommendations for Overcoming Challenges by ODL Student-Teachers from

Open Ended Questionnaires

Source: Field Data 2018 


\subsubsection{Overcoming Individual Challenges}

As it was to perceive individual challenges, as indicated in Table 1, the participants listed a number of perceived recommendations for overcoming individual challenges. On solving financial limitations, the majority (53.3\%) participants recommended the Government to support in-service ODL student-teachers financially. In relation to lack of skills of using computers and internets, $53.3 \%$ of the participants recommended for the ODL Centre to establish computer courses to equip ODL student-teachers with skills of using computers and internets. Similarly, on difficulty of getting learning materials, 33.3\% of participants recommended for ODL Centre should provide sufficient learning materials. On the same vein, $13.3 \%$ of the participants were in recommendation that the Government and ODL centre should subsidize the transport costs.

\subsubsection{Overcoming Institutional Challenges}

As indicated in Table 1 from open ended questionnaire recommendations for overcoming institutional challenges were listed. On absence of internets and networks in rural and remote areas, $46.7 \%$ of participants recommended for the Government to ensure that internets and networks in rural and remote areas should be available. On absence of computers and internet server at the ODL Centre, $80 \%$ of participants were on the views that ODL Centre had to install computers and internet server to enable student-teachers to access computer services, internets and e-mails. 33.3\% urged the Government to establish ODL Centres at least at district levels in Dodoma Region and other regions.

\subsubsection{Overcoming Instructional Challenges}

As indicated in Table 1, on overcoming the perceived instructional challenges, $33.3 \%$ of the participants were on recommendation that the ODL Centre should supply sufficient learning materials on time.13.3\% of participants recommended that time for face to face sessions should be extended were such as short time for face to face sessions, lack of frequent help from ODL facilitators, insufficient and delay of study materials, and delay of feedbacks from the Centre and ODL facilitators. ODL facilitators were recommended by $6.7 \%$ of participants to establish mechanisms of helping ODL student-teachers and provide feedback timely.

\section{Discussion}

The findings on perceived individual challenges in this study are in line with Budiman (2015) and Musingafi, Mapuranga, Chiwanza and Zebron (2015) who have indicated that ODL learners have limited time to study due to family and employment responsibilities. It is difficult for learners to balance the time to study and to work or do other life responsibilities or sometimes employer work demands take almost all their time. Meanwhile, ODL learners who are married and have children see that family responsibilities often prevent them from studying (Budiman, 2015).

As Budiman (2015) asserts, learners who do not know much how to use the laptops (computers) and modern technology face challenge in ODL programme. This affects ODL learners to find and access online learning materials. The findings in this study indicate that ODL participants lack skills of using computers and internets, and they have difficulty in getting learning materials. This concurs with other studies that ODL learners are challenged with both lack of experience in the application of technology and absence of these technologies (Basaza et al., 2010; Dodo, 2013; Mbukusa, 2009; Musingafi et al., 2015). This implies that ODL learners who cannot use the laptops (computers) and modern technologies are not satisfied and motivated with ODL programme. With this situation, their academic achievements are affected.

Financial constraint has received greater attention from participants in this study. This finding concurs other findings that financial limitation limit smooth learning in ODL programme and is one of the reasons for the dropouts of ODL learners or postponement of semesters (Dodo, 2013; Musingafi et al., 2015).

ODL requires constant and reliable access to technology such as computers, internet among others. It is important to note that internet access is fundamental for making open ODL efficient and effective. However, in most cases, constant internet is found in cities and hardly in rural areas (Matovu, 20120). According to Hara \& Kling (2003) as cited by Matovu (20120, the distasteful experience in internet inconsistence hinders the effective teaching and learning of distance learners. Therefore, in this study, the absence of internets and networks in rural and remote areas, absence of computers and internet server at the ODL Centre affect the ODL student-teachers in their learning processes. Some of the studentteachers who are from remote areas where internet connectivity is non-existent, their access to reading materials and or other information from ODL and their practice in the use of computers are limited (Dodo, 2013).

In relation to perceived instructional challenges, as this study indicates, participants are challenged with delayed and insufficient learning materials. This concurs with other studies that ODL learners have challenges related to insufficient and delayed study materials, especially modules, where most learners receive study materials late or never get them (Basaza et al., 2010; Musingafi et al., 2015). As Musingafi et al. (2015) reveal, in this situation learners are affected academically and psychologically. Lack of study materials force learners to submit assignments that are not properly written and they are likely to get to examinations without enough preparation resulting in poor performance.

As Ali and Ahmad (2011) point out, helps and feedback from instructors are related to learner satisfaction in ODL programme. Since challenges of helps and feedback from instructors in this study have received lesser attention from the participants, this means that participants are satisfied and motivated to learn at the Centre. According to Hurd (2007), absence of feedback coupled with isolation from lecturers and other learners has an impact on anxiety among distance learning learners.

The findings of this study also show that some participants, whatever few in number, perceive the absence of helps and feedback from ODL Centre and facilitators. This is in line with Musingafi et al. (2015) who proclaim that learners in ODL centres are unhappy with delayed or ineffective feedback on their performance. Therefore, this situation affects 
them in their motivation, satisfaction and achievement in ODL programme. Budiman (2015) stresses that absence of feedback from other people, especially ODL tutors, makes ODL learners mislay confidence in learning. Learners cannot know their strengths and weaknesses of their learning.

\section{Conclusion}

Many Tanzanians, including in-service teachers and Government, are benefiting, and will continue to benefit from ODL programmes. The programmes provide flexibility for learners, reduce the need for educational buildings, reduce transportation costs, allow learners to remain with their families and communities, and the tuition fees are relatively low. However, the learners face challenges as presented early in their course of learning. The most perceived challenges, among others, include: Individual challenges (meeting other activity demands while learning, failure to balance time for learning and doing other activities, financial limitations, lack of skills of using computers and internets hence difficulty to search online learning materials); institutional (absence of internets and networks in rural and remote areas, and absence of computer and internet server for students at the ODL Centre; and instructional (delayed feedback, and insufficient of study materials). This calls a combined action of Government, ODL centres and other ODL stakeholders reduce the challenges if not to eliminate them. This means that the perceived challenges are unlikely to be solved without collaboration involving the government, ODL centres and other ODL stakeholders.

\section{References}

i. Ali, A., \& Ahmad, I. (2011). Key Factors for Determining Students' Satisfaction in Distance Learning Courses: A Study of AllamaIqbal Open University. Contemporary Educational Technology, 2(2), 118-134.

ii. $\quad$ Basaza, G. N., Milman, B. N., \& Wright, C. R. (2010). The Challenges of Implementing Distance Education in Uganda: A Case Study. International Review of Research in Open and Distance Learning, 11(2), $84-91$.

iii. Budiman, R. (2015) D. STANCE LANGUAGE LEARNING: STUDENTS' VIEWS OF CHALLENGES AND SOLUTIONS.International Journal on New Trends in Education and Their Implications, 6 (3), 137 - 147.

iv. Dodo, 0. (2013). An Analysis of Challenges Faced by Students Learning in Virtual and Open Distance Learning System: A Case of Bindura University of Science Education (BUSE). Journal of Global Peace and Conflict, 1(1), 28 40.

v. Hurd, S. (2007). Anxiety and Non-Anxiety in a Distance Language Learning Environment: The Distance Factor as a Modifying Influence. System, 1-21.

vi. Institute of Adult Education (2008). Rolling Strategic Plan 2014/2015 - 2018/2019, Dar es Salaam: Author.

vii. James, R., Tynan, B., Baijnath, N., \& Teixeira, A. M. (2013). Open and Distance Education Policy Briefing. San Francisco: The International Council of Open and Distance Educators.

viii. Komba, W. L. M. (2009). Increasing education access through open and distance learning in Tanzania: A critical review of approaches and practices. International Journal of Education and Development using ICT, 5(5).।

ix. Mbukusa, N.R. (2009). Barriers to rural remote students' access of distance education supports services offered by the centre for External studies at the University of Namibia. Pretoria: University of South Africa.

x. Musingafi, M. C. C., Mapuranga, B., Chiwanza, K., \& Zebron, S. (2015). Challenges for Open and Distance learning (ODL) Students: Experiences from Students of the Zimbabwe Open University. Journal of Education and Practice, 6 (18), $59-66$.

xi. Onwe, J. O. (2013). Policies and Practice of Open and Distance Learning Models in the Sub-Saharan African Countries: A Literature Survey. American International Journal of Contemporary Research, 3 (8), 122 - 135.

xii. Özgür, A. Z., \& Koçak, N. G. (2016). Global Tendencies in Open and Distance Learning. Journal of Education and Human Development,5 (4), 202 - 210.

xiii. Rubanju, A. C. G. (2008). Quality challenges in higher education institutions in Uganda. M.Phil. Higher Education (HE), Faculty of Education, Institute for Educational Research. University of Oslo. Retrieved from http://www.uv.uio.no/studentliv/isne/assets/docs/Unit\%201\%20paper\%20assignment.doc

xiv. Soetan, A. K., Udoh, G. M., \& Suleiman, Z. (2015). Problems and Prospects of Open and Distance Learning: A Case of the Ilorin Study Centre. Malaysian Journal of Distance Education 17(1), 33-40.

xv. UNESCO. (2016). Global Education Monitoring Report 2016 Education for People and Planet: Creating Sustainable Future for All. Paris: The Author.

xvi. Matovu, M. (2012). DISTANCE EDUCATION IN UGANDA: ISSUES, OPPORTUNITIES AND CHALLENGES. Ontario International Development Agency, OIDA International Journal of Sustainable Development, 04 (09), 63 - 70. 